\title{
Fish Population Recruitment: What Recruitment Means and Why It Matters ${ }^{1}$
}

\author{
Edward V. Camp, Robert N. M. Ahrens, Angela B. Collins, and Kai Lorenzen²
}

\section{Abstract}

Recruitment is probably the most important process that regulates populations of fish, but it is complicated to understand. Recruitment refers to the process of small, young fish transitioning to an older, larger life stage. What is so important is that during the recruitment period, natural mortality is density-dependent in a compensatory manner. This means that whether a greater or a lesser number of eggs and larval fish are produced, the number of fish surviving to the subadult populations will be approximately the same. Recruitment processes are responsible for any fishery that is sustainable and are critically important to consider when making fisheries management decisions. This document explains what recruitment processes are, how they fit into fish life cycles, and why they are important for fisheries management.

\section{Why Fish Populations Are Important}

Fish populations and how they change are especially important to Florida. Here, a multitude of fish populations in fresh and saltwater support healthy ecosystems, provide people with food, and support economically important commercial and recreational fishing. Fishers receive income, enjoyment, or challenge from catching fish, and fishing supports local economies. Regardless of why people fish, fishing is an important part of many peoples' lives. This means that when fish populations change, humans as well as ecosystems are affected.

Fish populations can change through time for a variety of reasons. Specific processes that affect fish population change include fish growth (called somatic growth), fish reproduction (spawning), and fish death, which can occur from fishing (fishing mortality) or from natural causes (natural mortality). But probably the most important fish population process is also one of the trickiest to understand-"recruitment."

The purpose of this document is to explain the recruitment process in fish populations and why recruitment is so important to fisheries science and management. It does this by explaining

- what the term recruitment means in fisheries science;

- how recruitment fits into fishes' life cycles;

- the terms density-dependent mortality and densityindependent mortality; and

- how recruitment processes affect fisheries and fisheries management.

1. This document is FA222, one of a series of the School of Forest Resources and Conservation, Program in Fisheries and Aquatic Sciences, UF/ IFAS Extension. Original publication date March 2020. Visit the EDIS website at https://edis.ifas.ufledu for the currently supported version of this publication.

2. Edward V. Camp, assistant professor, Program in Fisheries and Aquatic Sciences, School of Forest Resources and Conservation; Angela B. Collins, UF/ IFAS Extension Florida Sea Grant agent, UF/IFAS Extension Manatee, Hillsborough, and Sarasota counties; Robert N. M. Ahrens, associate professor, Program in Fisheries and Aquatic Sciences, School of Forest Resources and Conservation; and Kai Lorenzen, professor, Program in Fisheries and Aquatic Sciences, School of Forest Resources and Conservation; UF/IFAS Extension, Gainesville, FL 32611.

The Institute of Food and Agricultural Sciences (IFAS) is an Equal Opportunity Institution authorized to provide research, educational information and other services

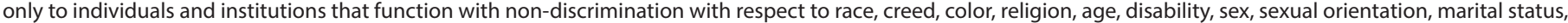

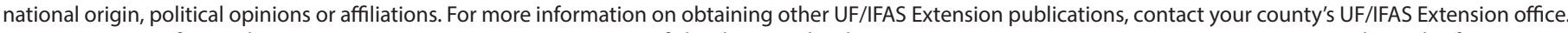
U.S. Department of Agriculture, UF/IFAS Extension Service, University of Florida, IFAS, Florida A \& M University Cooperative Extension Program, and Boards of County Commissioners Cooperating. Nick T. Place, dean for UF/IFAS Extension. 


\section{What "Recruitment" Refers to in Fisheries Science}

The term recruitment can refer to two separate processes in fisheries science-fish becoming vulnerable to harvest (e.g., reaching legal size), or fish transitioning to a different life stage. This document deals with the latter.

In fish life stages, the term recruitment process refers to the process by which very young, small fish survive to become slightly older, larger fish. Specifically, recruitment refers to the act of transitioning between two stages of life. This transition takes some time as the fish grow in size and often change their behavior (Walters and Juanes 1993). What is important is that before and after this transition, the rate at which fish die from natural mortality does not depend on the density of fish, density being the number of fish of a similar size and age in an area at a time. Fish mortality during the two stages before and after transition is called density-independent mortality. During the transitional period between these two stages, called the recruitment period, the natural mortality rate does depend on the density of the fish, and thus is called density-dependent mortality (Beverton and Holt 1957). So, a density-independent mortality rate (and survival rate) does not change depending on how many fish are in an area, and a density-dependent mortality rate (and survival rate) does change with fish density. Fish that survive the densitydependent-mortality recruitment stage are referred to as recruited fish or, simply, recruits.

\section{Important Terms for Recruitment}

Natural mortality: The rate of fish dying due to natural causes (i.e., not fishing) such as predation, disease, or old age.

Survival: The rate of fish not dying.

Recruitment process: The act of small fish transitioning to a larger size and greater age at which they will no longer experience density-dependent mortality.

Recruitment period: Refers to the time during which fish are going through the recruitment process, and in which we expect mortality to be density-dependent.

Recruited fish or "recruits": Fish that have just transitioned out of the recruitment period and now experience only density-independent mortality.

Density-dependent mortality: The natural mortality of fish (and thus their survival) depends on the numbers of fish in an area (which is the density); the type of mortality that occurs during the recruitment process.

Density-independent mortality: When the natural mortality (and survival) of fish does not depend on the numbers of fish in an area (density); typically occurs for very small fish (and eggs) that have not yet begun the recruitment period as well as for larger fish that have survived the recruitment period.

Settlement: Refers to larval fish beginning to associate with structural or physical habitat (i.e., "settling" out of the water column) and is usually associated with the beginning of the recruitment period.

Compensatory density-dependent mortality: when the mortality rate decreases (survival increases) with declining density of fish - this is what is assumed to occur during the recruitment period.

\section{How Recruitment Fits in Fish Life Cycles}

The fish life cycle can be broken up into several notable physical stages, in each of which mortality can be described as density-dependent or density-independent. Fish begin life as a fertilized egg that hatches into a larval fish or (or larva). Mortality for egg and larval stages is often considered density-independent because these tiny fish have less control over the habitats they occupy compared to larger fish (Jobling 1995). Once larval fish have developed enough to direct themselves, they often settle into structural habitat (like aquatic vegetation, corals, shallow areas, etc.) or aggregate into schools. This settlement phase is when most scientists think mortality begins to be density-dependent, and the recruitment period starts (Walters and Juanes 1993). As fish grow in size through the recruitment period, they become less vulnerable to predators (because relatively fewer predators are big enough to eat them, and they have fewer competitors for food and space). Eventually the fish will grow large enough that density-dependent mortality ceases and the fish are considered as recruited or recruit size (this probably occurs between $10 \%$ and $20 \%$ of the average maximum fish size; Lorenzen and Camp 2019).

After the fish recruit and become mature, they will be able to spawn and produce gametes (eggs or sperm). The number and quality of the eggs that female fish produce can vary, especially with body size and fish condition. While this may affect the contribution of an individual adult to the spawning population, or even the density-independent survival of eggs and larvae, all larval fish must still survive the density-dependent period to become a recruit. For 
this reason, recruitment is sometimes referred to as a "bottleneck" because it limits the number of fish surviving to larger sizes where they can be caught by fishers and eventually spawn to replenish the population.

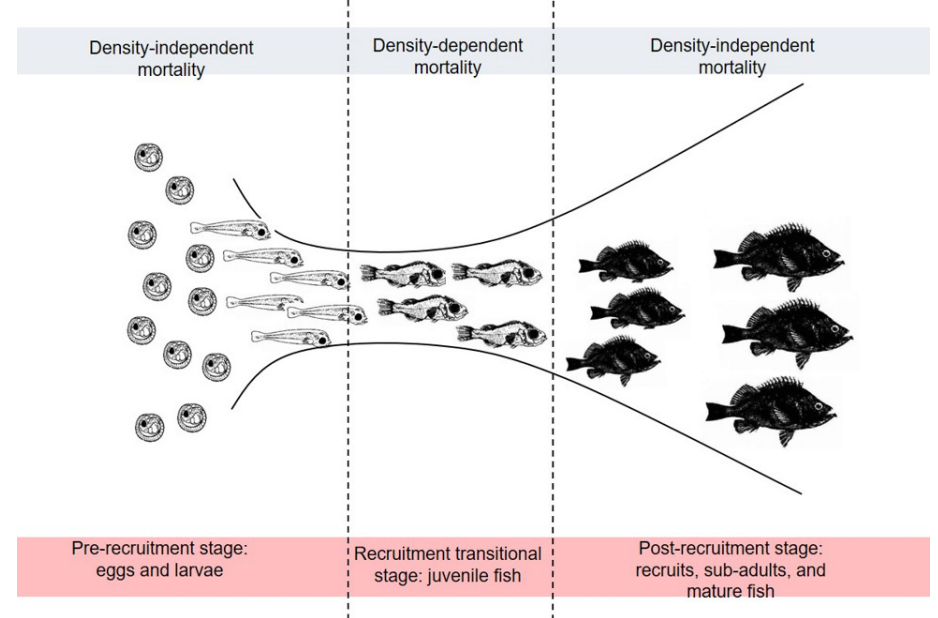

Figure 1. Diagram showing how the type of mortality (top shaded box) corresponds to fishes' life stage (bottom shaded box). Please note the number of fish here does not represent the survival, and the two "groups" of larger fish in the density-independent mortality section represent two age-classes.

Credits: Kai Lorenzen, UF/IFAS

\section{What Density-Dependent and Density-Independent Mortality Mean}

\section{Density Independent Mortality}

During the density-independent mortality stages, survival of an individual fish is not influenced by the number of other fish within the population. In other words, a fish dying during density-independent mortality stage will not result in the surviving fish having a different mortality or survival rate. For example, imagine a population of one hundred adult redfish with an expected $10 \%$ annual natural mortality rate. If an algal bloom (e.g., red tide) killed 30 fish early in the year, the remaining 70 fish would still be subject to the same $10 \%$ mortality rate-that means the mortality rate would not change or would be independent of the fish density. However, density independent mortality does not mean constant natural mortality. Different environmental conditions (ocean currents, temperatures, salinity) or perturbations (e.g., algal blooms, cold kills) could change mortality rates for fish in the density-independent stages during a certain time period. Density-independent mortality does mean that individual fish are not competing in a way that changes their mortality rate.

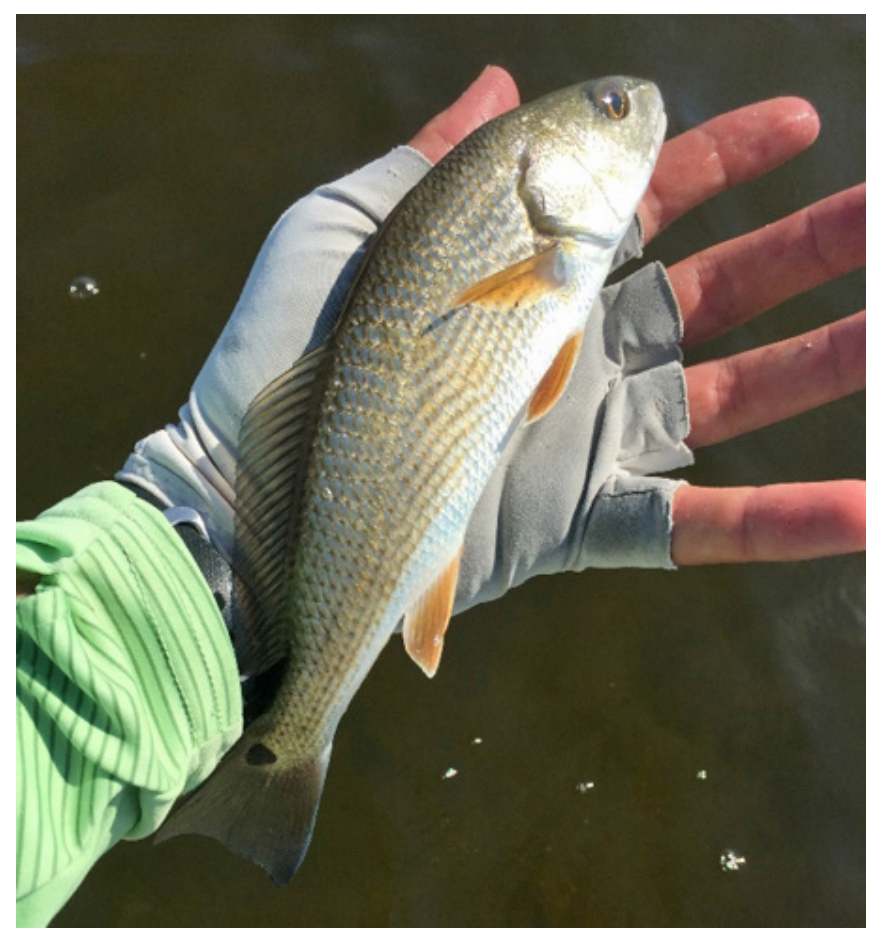

Figure 2. This red drum has almost certainly finished the recruitment process and would be called a "recruit." Credits: Edward Camp, UF/IFAS

\section{Density-Dependent Mortality}

Density-dependent mortality means that the mortality rate, and thus the survival rate, will change depending on the density of fish. Specifically, for the recruitment process, it is assumed that mortality will decrease (and therefore survival will increase) with decreasing density of fish-this is called compensatory density-dependent mortality (Rose et al. 2001). This means that the fewer fish in an area, the better they survive. This also means that for a wide range of densities of larval fish, the mortality rate will change (compensate) with density so that roughly a similar number of fish survive the recruitment period. This idea is based on the idea that resources during this period are the limiting factor for fish survival, and decreased densities reduce competition for food, space, and refuge (Walters and Juanes 1993). For example, if in one year there are 1000 larvae entering the recruitment period, and we expect about 100 to survive and become recruits, this would be a $90 \%$ mortality rate ( $10 \%$ survival rate). But if there were only 800 larvae entering the recruitment period, we would still expect about the same 100 to survive to become recruits. In the latter example, there is a lower, $87.5 \%$ mortality rate (12.5\% survival rate). This is illustrated in Figure 3. 
Example of density dependence
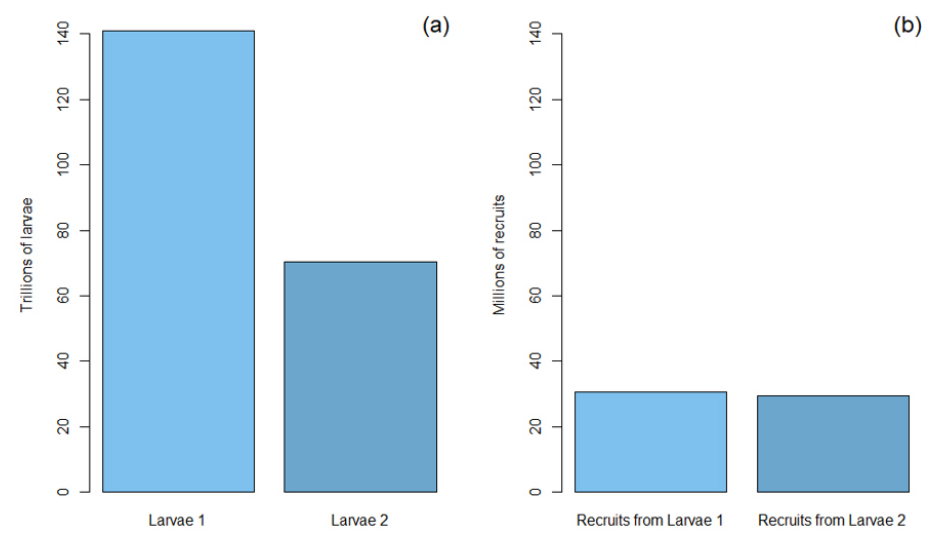

Figure 3. Hypothetical illustration of the effects of density dependence. Two amounts of larvae are shown in panel (a): Larvae 1 represents the larvae produced from an unfished spawning population, and Larvae 2 represents half of that. However, the recruits that each amount of larvae produces show almost no perceptible difference, in panel (b).

Credits: Edward Camp, UF/IFAS

\section{Why does compensatory, density- dependent mortality occur?}

There is actually much uncertainty about exactly what processes drive compensatory, density-dependent mortality (Rose et al. 2001; Lorenzen and Enberg 2002; Hazelrigg et al. 2012). One explanation is offered by the foraging arena theory (Walters and Juanes 1993; Ahrens et al. 2012). Forage arena theory suggests that small fish need to eat and avoid being eaten while living in water in which they can survive. There is usually a finite number of places that provide suitable conditions (temperature, oxygen, etc.) while also providing easy access to refuge from predators and food, and the best spaces are especially limited. When there are fewer fish, more of them get high-quality places. When there are many fish, some fish will fail to find bestquality refuge near food and thus will spend more time vulnerable when they are foraging. As a result, these fish may suffer greater mortality.

\section{Recruitment Trends}

So does the density-dependent mortality mean the number of fish recruiting each year should be about the same over time, as long as there is no major overfishing or environmental change? In theory, yes, but in practice, not exactly. Density-dependent mortality is expected to increase or decrease in healthy fish populations so that, on average, a similar number of fish survive the recruitment period. But in practice, the number of fish recruiting can vary quite a bit just from natural variation. And also, those factors that affect density-independent mortality (e.g., temperature, currents, algal blooms, etc.) can still affect mortality of fish during recruitment processes, even though mortality in this stage is also density-dependent. So, a fish population can still be very healthy and have variable recruitment. But long-term, declining trends in the numbers of fish recruiting can be evidence of a population problem, such as overfishing or loss of habitat. This is why research and monitoring programs are so important for effective fisheries management.

\section{What Recruitment Means for Fish Populations and Fisheries The Connection between Recruitment and Sustainable Fisheries}

The density-dependent mortality of the recruitment stage is exactly why fish may be harvested in large numbers while still maintaining sustainable fisheries. Simply put, densitydependent mortality means that the number of eggs hatching each year can decrease substantially (which it does when many mature fish are harvested) and still yield about the same number of recruits to the subadult populations.

If density-dependent recruitment processes didn't exist, fewer eggs would yield fewer subadults and thus adults, which would in turn produce fewer eggs to replenish the population. Continued fishing or simply natural variation would eventually drive populations to actual extinction. Compensatory density-dependent mortality explains stability in most natural systems and in fact must operate for any population to remain relatively steady over long time frames. The fact that many fish populations are heavily harvested but still exist (and sometimes even at sustainable levels) is evidence of substantial compensatory, densitydependent mortality.

\section{Why It Is Necessary to Consider Overfishing and Environmental Changes}

Compensatory, density-dependent mortality during the recruitment process is what allows some fisheries to be sustainable, but it does not guarantee all fisheries will be sustainable. If harvest rates are too high, too few adults can reduce the capacity of the population to replenish itself. Not enough spawning fish means not enough eggs will be produced and there will be a lack of larvae to "fill" the recruitment habitats. That means there will be more capacity for recruitment than there will be eggs or larvae to fill, resulting in a population that will be limited by the number of eggs and thus spawning adults.

Environmental changes like habitat loss or changes in food webs can also affect populations, sometimes in very strong ways. If there are declines in habitat that fish use while they are in the recruitment process, this can immediately 
change the maximum recruitment possible (Walters and Juanes 1993). Similar decreases may occur if the food that recruiting fish need is less available because this might effectively limit the spaces where there is sufficient refuge and forage (van Poorten et al. 2019; Camp et al. 2019). This is why understanding critical habitat and ecology of fish throughout their entire life history is so important for managing sustainable stocks.

\section{Recruitment Processes and Fisheries Management}

Nearly all fisheries management actions can have implications for recruitment processes. And, because recruitment processes drive population trends, recruitment processes are important to consider for most management actions. But some management actions are especially connected to recruitment. Stock enhancement (stocking) involves adding hatchery-reared fish to existing wild populations, and often the fish are stocked around the stages where they go through recruitment processes. If stocking leads to greater densities of fish going through the density-dependent recruitment process, it may not enhance populations as much as expected (Camp et al. 2014). The effectiveness of habitat restoration can also be affected by recruitment. Restoring critical nursery habitats that provide refuge and forage to recruiting fish can actually change the expected number of fish recruiting and thus the number available to fishers (Camp et al. 2019).

Recruitment processes also matter for determining the number of fish that can be sustainably harvested. Most harvest regulations, such as bag limits, size limits, or total allowable catch are intended to ensure there are enough adults producing enough eggs to ensure recruitment doesn't systematically decrease. Identifying exactly what that threshold is (i.e., the limit to how much an adult spawning population can be depleted before it is overfished) is not easy because it can vary between species or even populations of fish. What is important to understand is that the degree to which mortality can improve in a compensatory way determines, in part, how fish populations will respond to fishing, and thus how much fishing is sustainable.

Recruitment information is important, but difficult to estimate from commonly available data. This is because of the random and environmentally driven variation in the recruitment processes. To get good estimates of recruitment parameters, scientists typically need a time series of data several times as long as the average life span of the fish. Also, it is helpful if the time series includes variation in the abundance of the spawning population. This means that for a number of less-well-studied fish (for example, tripletail,
Lobotes spp.), little information on recruitment exists. To address this, fisheries scientists have performed large, synthesis-type studies that allow them to make broader generalizations that provide some helpful information for these species that haven't been individually well-studied (Myers 1999; Rose et al. 2001).

\section{What about other animals besides finfish?}

The same principles of recruitment (density-dependent and compensatory survival) surely exist for other animals like crabs, scallops, or oysters. However, many of these organisms are not as well-studied as certain finfish populations, but some species that support commercial fisheries (especially lobsters and crabs) have been studied (Wahle 2013). Also, certain animals that help construct their own habitat (like oysters) will almost certainly have different and more complicated types of recruitment and density-dependent survival.

\section{Conclusion}

The density-dependent mortality that occurs during early fish life stages is one of the most important dynamics affecting fish populations. It means that over a wide range of numbers of eggs spawned, the numbers of fish recruiting to subadult populations can be similar through time (on average; there is still room for a lot of annual variability). Density-dependent recruitment processes are also the reasons that populations can sustain themselves even when a large number of adults die from fishing or natural causes. However, density-dependent recruitment processes cannot compensate infinitely. Severe overfishing or reductions in suitable habitat can lead to reduced numbers of recruits and decreased population levels. Nearly every fishery management action, whether it is designed to limit fishing mortality or to enhance populations through stocking or habitat restoration, needs to be explicitly considered in the context of how the action will affect expected recruitment. For all of these reasons, it is exceptionally important for scientists and managers to study trends in recruitment and understand how natural processes and management actions affect this vital life-history stage. 


\section{References}

Ahrens, R. N., C. J. Walters, and V. Christensen. 2012. "Foraging Arena Theory." Fish and Fisheries 13(1): 41-59.

Beverton, R. J. H., and S. J. Holt. 1957. On the Dynamics of Exploited Fish Populations. United Kingdom Ministry of Agriculture and Fisheries, Fishery Investigations, Series II, 19.

Camp, E. V., R. N. Ahrens, T. C. MacDonald, K. A. Thompson, and K. Lorenzen. 2019. "Identifying Forage Populations of Concern: A New Perspective Based on Predator Recruitment Considerations." Fisheries Research 219: 10.1016/j.fishres.2019.105319.

Camp, E. V., K. Lorenzen, R. N. M. Ahrens, and M. S. Allen. 2014. "Stock Enhancement to Address Multiple Recreational Fisheries Objectives: An Integrated Model Applied to Red Drum Sciaenops ocellatus in Florida." Journal of Fish Biology 85(6): 1868-1889.

Camp, E. V., K. Lorenzen, and M. D. Taylor. nd. "Impacts of Habitat Repair on a Spatially Complex Fishery." Estuarine, Coastal and Shelf Science. In press.

Hazlerigg, C. R., K. Lorenzen, P. Thorbek, J. R. Wheeler, and C. R. Tyler. 2012. "Density-Dependent Processes in the Life History of Fishes: Evidence from Laboratory Populations of Zebrafish Danio rerio." PLoS One 7(5) e37550.

Jobling, M. "Fish Bioenergetics." 1995. Oceanographic Literature Review 9(42): 785.

Lorenzen, K. 1996. “The Relationship between Body Weight and Natural Mortality in Juvenile and Adult Fish: A Comparison of Natural Ecosystems and Aquaculture." Journal of Fish Biology 49(4): 627-642.

Lorenzen, K., and E. V. Camp. 2019. "Density-Dependence in the Life History of Fishes: When Is a Fish Recruited?" Fisheries Research 217: 5-10.

Lorenzen, K., and K. Enberg. 2002. "Density-Dependent Growth as a Key Mechanism in the Regulation of Fish Populations: Evidence from Among-Population Comparisons." Proceedings of the Royal Society of London. Series B: Biological Sciences 269(1486): 49-54.

Myers, R. A., K. G. Bowen, and N. J. Barrowman. 1999. "Maximum Reproductive Rate of Fish at Low Population Sizes." Canadian Journal of Fisheries and Aquatic Sciences 56(12): 2404-2419.
Rose, K. A., J. H. Cowan, K. O. Winemiller, R. A. Myers, and R. Hilborn. 2001. "Compensatory Density Dependence in fish Populations: Importance, Controversy, Understanding and Prognosis." Fish and Fisheries 2(4): 293-327.

Van Poorten, B., J. Korman, and C. Walters. 2018.

"Revisiting Beverton-Holt Recruitment in the Presence of Variation in Food Availability." Reviews in Fish Biology and Fisheries 28(3): 607-624.

Wahle, R. A. 2003. "Revealing Stock-Recruitment Relationships in Lobsters and Crabs: Is Experimental Ecology the Key?" Fisheries Research 65(1-3): 3-32.

Walters, C. J., and F. Juanes. 1993. "Recruitment Limitation as a Consequence of Natural Selection for Use of Restricted Feeding Habitats and Predation Risk Taking by Juvenile Fishes." Canadian Journal of Fisheries and Aquatic Sciences 50(10): 2058-2070. 